\title{
Comment on "Comparison of neutrophil lymphocyte ratio, platelet lymphocyte ratio and mean platelet volume and PCR test in Covid-19 patients"
}

\author{
Mehmet Zahid Kocak' ${ }^{1}$
}

Dear Editor,

We read with pleasure the article by Ozsari et al. ${ }^{1}$, on the association between lymphocyte ratio (NLR), platelet lymphocyte ratio (PLR), and mean platelet volume (MPV) levels and PCR test results and thorax tomography (CT) findings in Covid-19 patients. The Covid-19 disease is a pandemic that affects the whole world and causes many deaths. Early diagnosis and start early treatment was very important to prevent deaths due to the Covid-19 disease. PCR test, CT findings, NLR, and acute phase reactants are used in the diagnosis of Covid-19 disease. In this manuscript, the authors assessed the diagnostic value of NLR, PLR, and MPV according to PCR test and CT findings. This cross-sectional study provided varied significant outcomes. For this aim of analysis, we congratulate the authors, and we want to discourse some subjects that deserve more interest.

The diagnostic and prognostic importance of NLR and PLR in Covid-19 patients has been reported in various studies ${ }^{2,3}$.
Recently studies have reported that the diagnostic value of NLR and PLR is not certain ${ }^{4}$. However, discordance in PCR test results and CT findings were not mentioned in these studies. In this context, this study is very valuable. On the other hand, we want to mention that; it is not reported that patients who are negative for PCR become positive or remain negative in their repeated tests. The interpretation that the inflammation was severe in the CT positive-PCR negative group was somewhat ambitious. There is no data that the PCR test is negative due to the severity of inflammation. We think that this negativity is due to the sensitivity and specificity of the PCT test.

Consequently, as in this study, hemogram parameters such as NLR and PLR are valuable markers in the diagnosis of Covid-19 $9^{2,3}$. However, more studies are needed for the relationship between hemogram parameters and PCR test and CT findings.

\section{REFERENCES}

1. Ozsarı S, Ozsarı E, Demirkol M. Comparison of neutrophil lymphocyte ratio, platelet lymphocyte ratio and mean platelet volume and PCR test in Covid-19 patients. Rev Assoc Med Bras. 2021;67(suppl 1):40-5. https://doi.org/10.1590/18069282.67.Suppl1.20200630

2. Nalbant A, Kaya T, Varim C, Yaylaci S, Tamer A, Cinemre H. Can the neutrophil/lymphocyte ratio (NLR) have a role in the diagnosis of coronavirus 2019 disease (COVID-19)? Rev Assoc Med Bras. 2020;66(6):746-51. https://doi.org/10.1590/1806-9282.66.6.746
3. Qu R, Ling Y, Zhang YH, Wei LY, Chen X, Li XM, et al. Plateletto-lymphocyte ratio is associated with prognosis in patients with coronavirus disease-19. J Med Virol. 2020;92(9):1533-41. https://doi.org/10.1002/jmv.25767

4. Pereira MAM, Barros ICA, Jacob ALV, Assis ML, Kanaan S, Kang HC. Laboratory findings in SARS-CoV-2 infections: state of the art. Rev Assoc Med Bras. 2020;66(8):1152-6. https:// doi.org/10.1590/1806-9282.66.8.1152

\footnotetext{
${ }^{1}$ Necmettin Erbakan University, Department of Internal Medicine - Konya, Turkey.

*Corresponding author: mehmetzahidkocak@hotmail.com

Conflicts of interest: the authors declare there are no conflicts of interest. Funding: none.

Received on December 10, 2020. Accepted on December 13, 2020.
} 